\title{
Application of Osthol Induces a Resistance Response Against Powdery Mildew in Pumpkin Leaves
}

\section{Zhiqi Shi $^{1,2, \#, *}$, Fei Wang ${ }^{2, \#, ~ W e i ~ Z h o u ~}{ }^{2}$, Peng Zhang $^{3}$ and Yong Jian Fan ${ }^{1}$}

1 Department of Plant Protection of Nanjing Agricultural University, Nanjing210095, China;

E-mail: shizhiqi@jaas.ac.cn; yjfan@jaas.ac.cn

2 Food Safety institute, Jiangsu Academy of Agricultural Sciences, Nanjing 210014, China;

E-mail: zhmdwf@jaas.ac.cn; zhouw811@jaas.ac.cn; shizhiqi@jaas.ac.cn

3 Institute of Biotechnology, Jiangsu Academy of Agricultural Sciences, Nanjing 210014, China;

E-mail: jszhangpeng@jaas.ac.cn

* Author to whom correspondence should be addressed. Tel.: +86-025-84391863; Fax: +86-02584391260; E-mail: shizhiqi@jaas.ac.cn;

\# Both Authors contributed equally to this work.

Received: 30 May 2007; in revised form: 20 August 2007 / Accepted: 6 September 2007 /

Published: 14 September 2007

\begin{abstract}
Plants can defend themselves against fungal infection by natural means induced by biotic and abiotic elicitors. Osthol is a natural compound extracted from dried fruits of Cnidii Monnieri Fructus. In this study, it has been shown to not only be a fungicide with acceptable curative properties (control efficacy of 68.72), but it also showed a significant prophylactic effect (with control efficacy of 77.36) against pumpkin powdery mildew at a concentration of $100 \mu \mathrm{g} \cdot \mathrm{mL}^{-1}$. In pumpkin leaves with/or without inoculation of Sphaerotheca fuliginea, osthol treatment induced the accumulation of chitinase and peroxidase and enhanced the transcription of chitinase gene in non-inoculated leaves. The potentiation of phenylalanine amonia-lyase activity in leaves by osthol application and following inoculation was absent in that with inoculation or osthol treatment, indicating that induced PAL in osthol-pretreated plants was inoculation-mediated. In conclusion, this natural compound could induce resistance response in the plant against powdery mildew.
\end{abstract}

Keywords: Osthol, coumarinic compound, induced resistance response, Cucurbita moschata, Sphaerotheca fuliginea, chitinase, POD, PAL 


\section{Introduction}

Plants have constitutive and induced mechanisms to defend themselves against pathogenic agents. The induced mechanism has been widely studied, and many abiotic or biotic components have been exploited for their eliciting properties to induce resistance [1,2].

Pathogenesis-related proteins consist of enzymes including chitinase peroxidase, phenylalanine amonia-lyase and certain other proteins which accumulate to high levels following pathogen attacks. Their induction has been correlated with greater resistance to subsequent pathogen attack [3]. Chitinases catalyze the hydrolysis of $\beta$-(1-4) linkages in the linear homopolymer, chitin. A role for chitinases in plant defense against fungal attack is suggested by the absence of chitin in higher plants, its presence in fungal cell walls [4], and the finding that plant chitinases inhibit spore germination and mycelia growth of certain fungi in vitro [5,6]. Chitinases are constitutively expressed at low levels in leaves and at high levels in roots [7]. Increased levels of the gene expression or the enzymic activity have been observed in leaves after inoculation with pathogenic microbe [8-10].

Osthol is a coumarinic compound (7-methoxy-8-[3-methylpent-2-enyl] coumarin), extracted from dried fruits of Cnidii monnieri Fructus. Traditionally, osthol is used as an external medicine for the treatment of eczema, cutaneous pruritus and Ttrichomonas vaginalis, and an internal medicine for frigidity [11,12]. Recent pharmacological studies have revealed it to possess antiallergic [13], antiosteoporotic [14] and anti-inflammatory activities [15]. Its antifungal activity was proven on Alternaria alternate, A. ergillus sp., Cryptococuus neoformans, etc. [16]. Our previous studies also showed that osthol has a wide antifungal activity, with the $\mathrm{EC}_{50}$ value ranging from $21.15 \mu \mathrm{g} \cdot \mathrm{mL}^{-1}$ to $61.62 \mu \mathrm{g} \cdot \mathrm{mL}^{-1}$ against Rhizoctonia solani, Colletotrichum mllsae, Phytophora capsici and other phytopathogenic fungi [17]. Coumarin, as an allelochemical, sufficiently affects the overall root growth and morphology and the root type at the concentration of $0.25 \mathrm{mM}[18,19]$, but no evidence concerning about the increased resistance in host plant responses to coumarinic compounds has been reported.

Pumpkin powdery mildew (caused by Sphaerotheca fuliginea) heavily affects yield and quality of pumpkins (Cucurbita moschata Duch) produced for market every year. During our study of antifungal activity of osthol against powdery mildew on pumpkin we found that this natural compound can act as not only a curative fungicide, but also as a preventative agent. We also analyzed the expression of chitinases and other pathogenesis-related protein in tissues of pumpkins treated by osthol.

\section{Results and Discussion}

\subsection{Results}

\subsubsection{Effect of osthol on powdery mildew infection of pumpkin}

Seven days after inoculation, the powdery mildew disease index on every plant was estimated. The water control plants had a disease index of 72.35, significantly higher than those of 15.56 and 22.63 for osthol applications before and after inoculation. However, there were no significant differences between the curative and preventive effects of osthol against powdery mildew on pumpkin. The concentration of $100 \mu \mathrm{g} \cdot \mathrm{mL}^{-1}$ showed the best control efficacy whatever the time of inoculation (Table 1). 
Table 1. Assessment of the efficacy of osthol against powdery mildew on cucumber leaves

\begin{tabular}{lll}
\hline Treatment & Mean (Disease index) & Control efficacy $^{\mathbf{b}}$ \\
\hline Osthol $\left(100 \mu \mathrm{g} \cdot \mathrm{mL}^{-1}\right)$ before inoculation & $15.56 \mathrm{c}$ & 77.36 \\
Osthol $\left(50 \mu \mathrm{g} \cdot \mathrm{mL}^{-1}\right)$ before inoculation & $42.22 \mathrm{~b}$ & 41.64 \\
Osthol $\left(100 \mu \mathrm{g} \cdot \mathrm{mL}^{-1}\right)$ after inoculation & $22.63 \mathrm{c}$ & 68.72 \\
Osthol $\left(50 \mu \mathrm{g} \cdot \mathrm{mL}^{-1}\right)$ after inoculation & $50.78 \mathrm{~b}$ & 29.81 \\
Water control & $72.35 \mathrm{a}$ & \\
\hline
\end{tabular}

Disease assessment was carried out 5 days after the inoculation. The interval between the osthol application and fungal inoculation was 2 days.

a values represent means of Disease Index made on 10 plants. Mean values followed by the same letter in each column do not differ statistically. Data were subjected to one-way analyses of variance and mean separation was performed using LSD tests $(\mathrm{a}=0.05)$.

${ }^{\mathrm{b}}$ Control efficacy was determined from disease index $\left(\frac{\text { water control }- \text { osthol treatment }}{\text { water control }} \times 100\right)$.

\subsubsection{Enzyme Assays}

Enzyme activities of chitinase, peroxidase (POD) activity and phenylalanine amonia-lyase (PAL) in pumpkin leaves were assayed using colloidal chitin, $\mathrm{H}_{2} \mathrm{O}_{2}$ and $L$-phenylalanine as substrates, respectively. Although inoculations were carried out 2 days after the osthol application, the activities were measured from the first day of osthol application.

Figure 1. Chitinase activity in pumpkin leaves upon osthol application and/or S. fuliginea inoculation. Non-osthol-treated and non-inoculated plants (WO), plants treated with osthol and non-inoculated (SO), non-osthol-treated plant inoculated (WI) and ostholtreated plant inoculated with $S$. fuliginea (SI). Each value is the mean \pm S.E. for $n=3$.

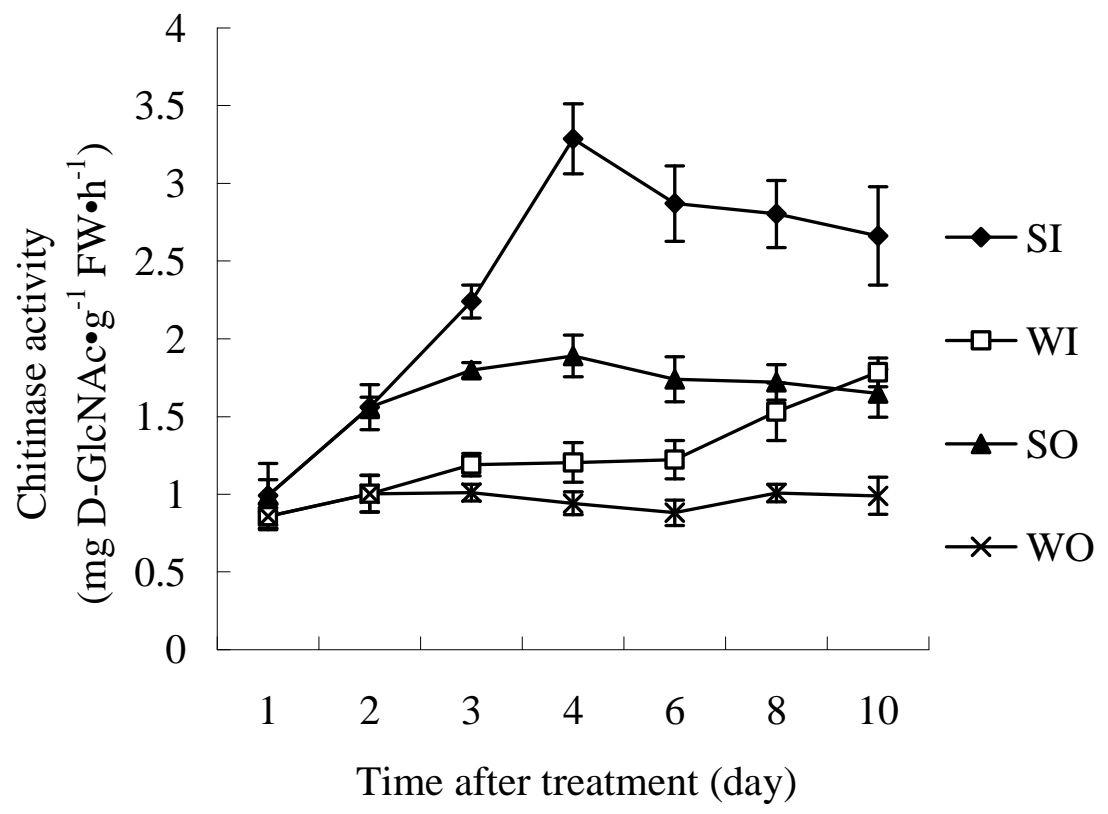


Overall, osthol treatments markedly increased chitinase activity in leaves of pumpkin, compared to the remaining treatments (Figure 1). In plants (SI) treated with osthol and inoculated by S. fuliginea, increased chitinase activity by two days (1.56) after osthol treatment, reaching the maximum level (3.29) after four days, followed by plants (SO) treated with osthol but non-inoculated and control plants. Activity of chitinase in inoculated leaves (WI) showed a slow increase, and the activity kept a low level in leaves of non-osthol-treated and non-inoculated pumpkin (WO) throughout the experimental period.

Figure 2. Peroxidase activity in pumpkin leaves upon osthol application and/or $S$. fuliginea inoculation. Non-osthol-treated and non-inoculated plants (WO), plants treated with osthol and non-inoculated (SO), non-osthol-treated plant inoculated (WI) and ostholtreated plant inoculated with $S$. fuliginea $(\mathrm{SI})$. Each value is the mean \pm S.E. for $n=3$.

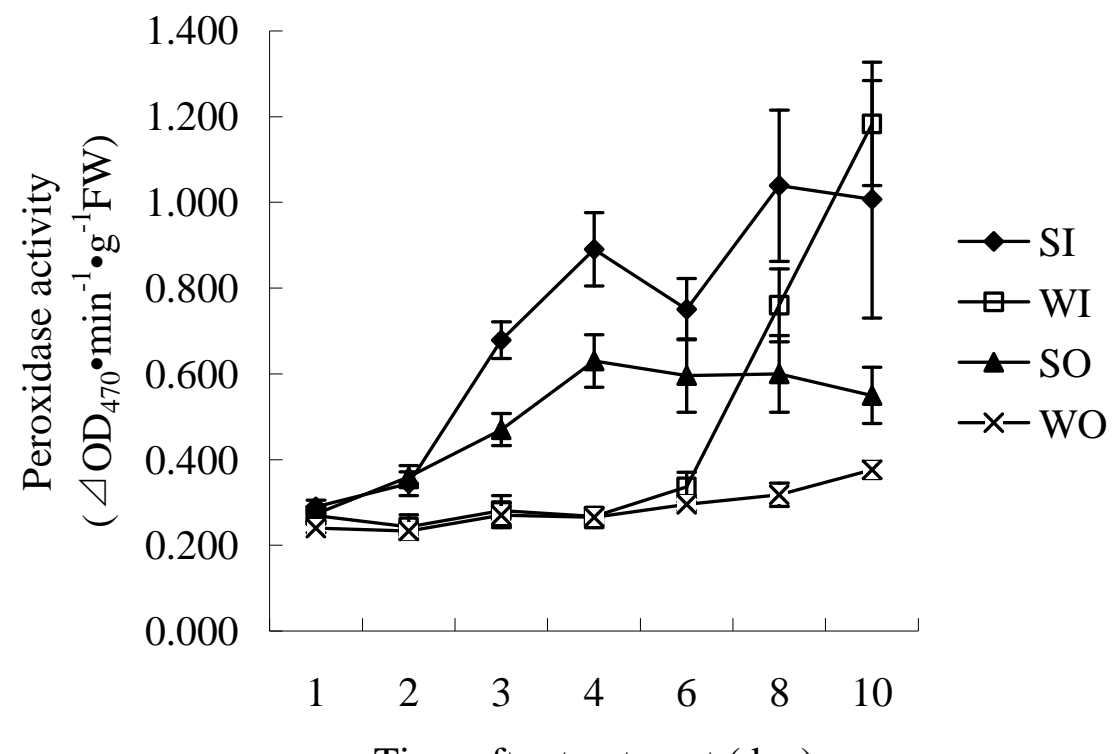

Time after treatment (day)

After osthol application, the activities of POD in leaves of pumpkin began to rise (SI and SO) (Figure 2). Especially, the following inoculation on the second day significantly $(\mathrm{P} \leq 0.05)$ increased its activity, and on the fourth and eighth day, the activity of POD appeared two peaks (0.89 and 1.04) in osthol-treated and inoculated plants (SI). During the whole sampling time, the POD activity of ostholtreated plants with no inoculation (SO) was higher than non-treated and non-inoculated control (WO), and the activity peak appeared on the fourth day was much lower (0.63). As to plants inoculated but not osthol-pretreated (WI), the POD activity was little changed during the first six days, showing no difference with the (WO) control, and then the activity showed a dramatically increase till the end of test sampling period.

According to Figure 3, the activity of PAL in the control plant is very low (WO), and the inoculation of $S$. fuliginea or application of osthol caused no change in the basal level of PAL. However, the activity increased rapidly from second day (0.05) after inoculation of S. fuliginea in osthol-pretreated plant (SI), and reached the maximum level (0.075) on the sixth day. From the second day, its activity in SI plants maintaining higher all along then other treatments. 
Figure 3. PAL activity in pumpkin leaves upon osthol application and/or S. fuliginea inoculation. Non-osthol-treated and non-inoculated plants (WO), plants treated with osthol and non-inoculated (SO), non-osthol-treated plant inoculated (WI) and ostholtreated plant inoculated with $S$. fuliginea (SI). Each value is the mean \pm S.E. for $n=3$.

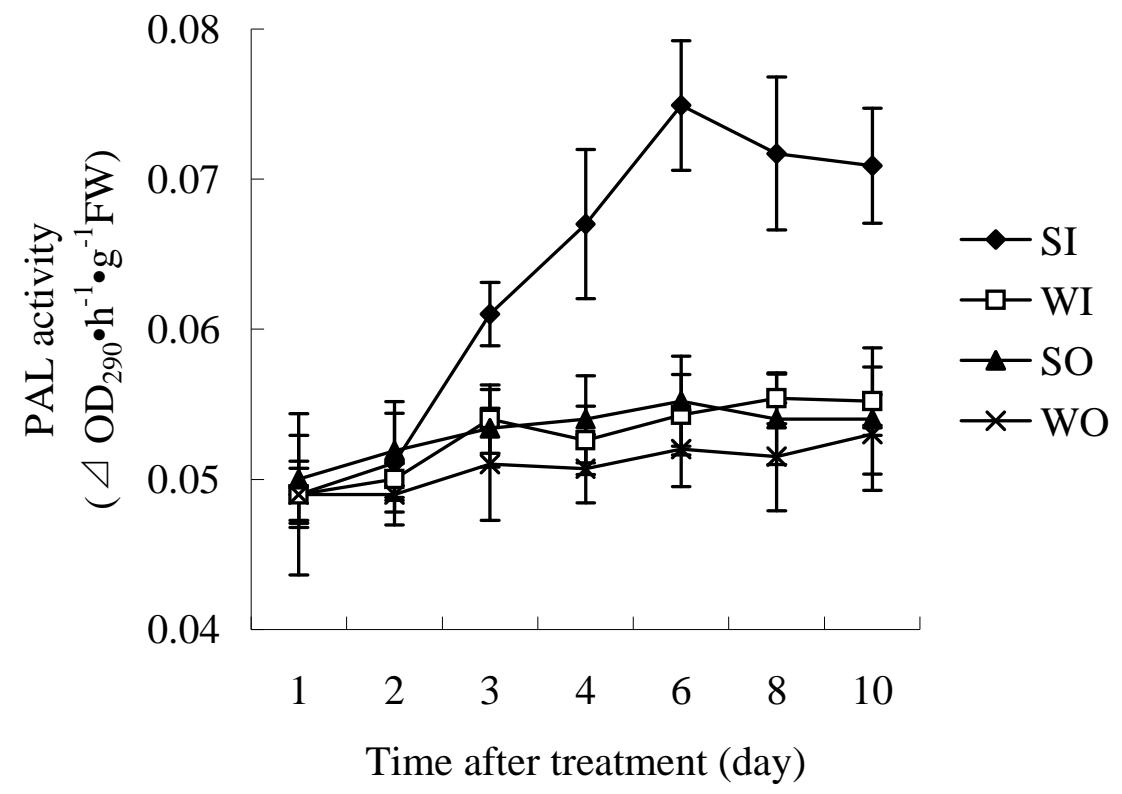

\subsubsection{Chitinase gene (Chitin) transcription}

To examine the expression of the Chitin gene response to the osthol treatment, we isolated total RNA from leaves of osthol-treated pumpkin. RT-PCR was used to generate cDNA and amplification products by using primers specific for Chitin and, as a control, primers corresponding to the actin cDNA. Using this approach, a fragment with lengths of $329 \mathrm{bp}$ was obtained (accession number in the GenBank: EU056338). We found that Chitin could be constructively expressed (Figure 4B, Ck). But osthol treatment could also greatly increase the expression (Figure 4B, Os).

\subsection{Discussion}

In this study, we investigated the influence of pretreatment of pumpkin with osthol on the powdery mildew control and the activation of pathogenesis-related proteins. We confirmed that applications of osthol on pumpkin leaves both before and after inoculation reduced the disease index. Giving that the accumulation of these proteins after pathogen infection correlates with induced resistance [20], we used the activities of chitinase, POD and PAL as indicators of the activation of the defense response [21]. Osthol application by spraying proved to be the inducer of chitinase, POD accumulation. To our knowledge, this is the first report suggesting that a coumarinic compound could be a prophylactic agent against powdery mildew on pumpkin through stimulating a resistance response in the host plant. An induction period required by agents is an interval of time between application of the agent and the challenge from the pathogen. In most cases it was reported to lie between one and seven days [22]. In our study, in order to assess both the efficacies of protective and curative, the potentiation of defense in plants by osthol was assessed five days after the inoculation [23]. Longer periods provided no significant difference from the assessment data (data not shown). 
Figure 4. Increase in expression of Chitin in osthol-treated pumpkin. Chitin was amplified by RT-PCR from total RNA derived from osthol-treated pumpkin (Os), with plant treated with water as control. The expected size of the resulting cDNA fragment was $329 \mathrm{bp}$ (B). As an internal control, the actin transcript was also amplified by RT-PCR (A). Sizes of the molecular length standards (M) run in parallel are indicated at the left.

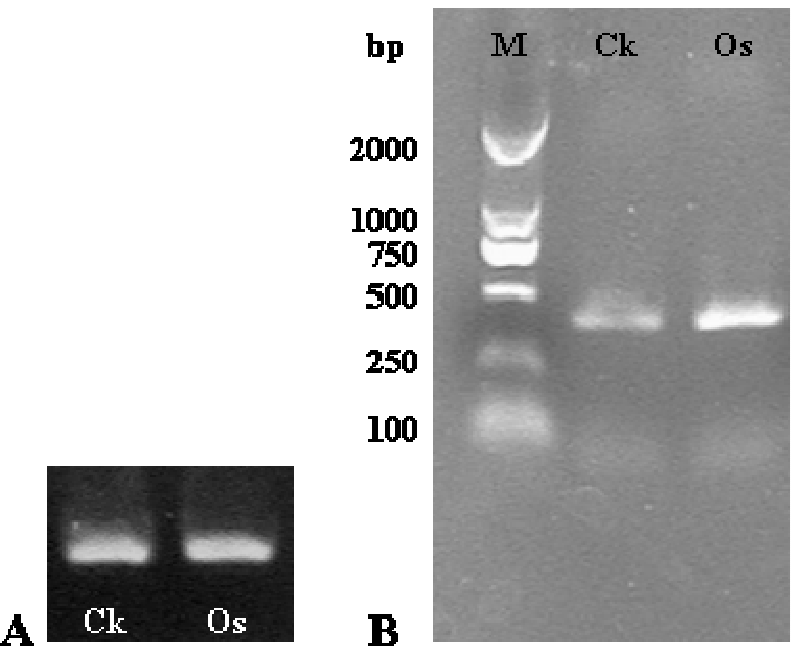

The visual assessment of disease development as measured by mildew covering the leaf surface demonstrated both the protective and curative roles of osthol on pumpkin. In these experiments, osthol $\left(100 \mu \mathrm{g} \cdot \mathrm{mL}^{-1}\right)$-treated plants had a level of infection about 4-fold lower than untreated plants. The curative roles could be derived from fungicidal efficacy of the compound [17]. The protective roles suggested the resistance response in the plants induced by osthol application.

Identifying induced proteins such as chitinase, peroxidase, PAL, etc., could provide and elucidate plant defense responses. We used enzyme assays and RT-PCR differential display of chitinase in osthol-treated cucumber plants to detect defense-response proteins and mRNA.

Chitinases in plants showed a close relationship with resistance against pathogens. The enzymes also can be induced by wounding or by exposure to ethylene, fungal cell wall preparations, or abiotic elicitors such as salicylic acid (SA) and mercuric chloride [24,25]. The high peroxidase activities are usually associated with later stages of the infection process and are linked to lignification and generation of hydrogen peroxides that inhibit pathogens directly or generate other free radicals with antimicrobial effects [26,27]. In this paper, osthol treatment increased the activities of these enzymes in the pumpkin leaves. The following inoculation of caused to the highest chitinase and peroxidase activities in all treatments, indicating the strong resistance response in the host plant against $S$. fuliginea.

PAL is the first and a key enzyme of the phenylpropanoid pathway that leads to the synthesis of benzoic acid, SA and a variety of other phenol defense-related plant secondary metabolites [28]. The activation of PAL activity is an early, common and important response of plant to biotic and abiotic stresses [29]. In this paper, PAL activity was not increased after inoculation or osthol treatment. However, which could be strong increased by treatment of osthol application and following inoculation. This indicated that the potentiation by osthol of PAL activity in pumpkin leaves was mediated by the inoculation. This may be results of a special signal pathway of PAL unlike that of 
POD and chitinase. In previous research about the relationship of the induced resistance to phenol metabolism, Rémus-Borle et al. reported that response in wheat plants against Blumeria graminis f.sp. tritici could be activated by silicon treatment. The presence of several antifungal compounds were not found in wheat plants that were treated with silicon but not inoculated nor were they found in inoculated plants that had not been pretreated with silicon $[1,30]$. It seems that osthol shares same signal transduction model with silicon to activate the phenol metabolism.

Application of osthol induced a progressive and significant increase of the enzymes, chitinase and POD. Such responses were more dramatic in osthol-treated plants challenged with S. fuliginea, thus providing support to the concept that a triggering signal produced by inoculation is essential to further enhance synthesis and accumulation of defense relative products of chitinase, POD and PAL [27].

Plants can be induced to become more resistant to disease through various biotic or abiotic elicitors [31]. Various chemicals such as 2,6-dichloroisonicotinic acid (INA) and its derivatives, the benzo1,2,3-thiadiazole derivatives like S-methylbenzo-1,2,3-thiadiazole-7-carbothiate [32,33], various salts (phosphates, silicates and oxalates) [34,35], probenazole [36], D, $L$ - $\beta$-aminobutyric acid (BABA) [37,38], 2,2-dichloro-3,3-dimethylcyclopropane carboxylic acid [39], salicylic acid (SA), jasmonic acid (JA), chitosan, etc. [35] have been discovered which seem to mimic the biological activation of resistance. However, coumarinic osthol was not reported. Of these compounds, only BABA has also been reported to display a curative effect $[37,38]$, properties similar to those now seen in osthol, but the mode of action of proposed resistance induction by BABA has not been clearly elucidated $[23,40,41]$.

Plant elicitors are of interest for their function to activate plants' own natural defenses against phytopathogens [27]. Osthol proved to be an efficient elicitor of defense mechanisms in pumpkin. Giving that osthol is an efficient fungicide, its application may be more convenient in the field to control powdery mildew and other potential pathogens. If integrated properly in plant health management programs, such compounds can prolong the useful life of both the resistance genes in plant and the fungicides [33].

\section{Experimental Section}

\subsection{Plant material and osthol}

Pumpkin (C. moschata) seeds were obtained from Tomorrow Seed Company (Jiangsu province, P.R. China). Surface sterilization was performed by mixing with $70 \%$ (v/v) ethanol for $10 \mathrm{~min}$ on a magnetic stirrer. Then seeds were rinsed in distilled water for $1 \mathrm{~min}$. Germination of the seeds was in $100 \%$ humidity for 7 days in the dark. Geminated seeds with two cotyledons were transferred to Hoagland liquid medium grown further in a greenhouse maintained at $25^{\circ} \mathrm{C}$ with a relative humidity of $80 \%$ and a photoperiod of 16/8 (light/dark) h/d. Experiments were carried out when seedlings were in four-leaf stage. Osthol (99.5\%) used in this study was purchased from NICPBP (National Institute for the Control of Pharmaceutical and Biological Products, Beijing, P. R. China). Freshly prepared osthol at a concentration of 50 or $100 \mu \mathrm{g} \cdot \mathrm{mL}^{-1}$ was applied in the assessment trial on osthol efficacy against powdery mildew. All the other reagents were of analytical grade. Our previous field study showed that the concentration of $100 \mu \mathrm{g} \cdot \mathrm{mL}^{-1}$ could effectively control powdery mildew on pumpkin. 


\subsection{Treatment, pathogen inoculation and disease assessment}

A field isolate of $S$. fuliginea from an infected pumpkin seedling was used. Cultures of powdery mildew were maintained by transfer of conidia to fresh sterile seedlings every two or three weeks. One day before the inoculation, heavily infested leaves were shaken to displace older spores and ensure that conidia were freshly formed. Plants were randomly assigned to five groups of 10 replicates and were sprayed to run-off with (i) water (untreated control); $50 \mu \mathrm{g} \cdot \mathrm{mL}^{-1}$ osthol treatments comprised (ii) "osthol" application two days before inoculation; and (iii) "osthol" application two days after inoculation $100 \mu \mathrm{g} \cdot \mathrm{mL}^{-1}$ osthol treatments comprised (iv) "osthol" application two days before inoculation; and (v) "osthol" application two days after inoculation. Plants in treatments were inoculated by shaking sporulating colonies of pumpkin mildew over the leaves of plants to be infected. Disease assessment was carried out five days after the inoculation. The infection degree was assessed visually using a $0-5$ scale: where $0=$ no disease symptoms, $1=$ less than $1 / 5$ of the host surface covered by mycelia, $2=1 / 5-1 / 3$ of the surface covered by mycelia, $3=1 / 3-1 / 2$ of the surface covered by mycelia, $4=1 / 2-2 / 3$ of the surface covered by mycelia, $5=$ more than $2 / 3$ of the surface covered by mycelia. Disease index of every plant was determined, according to the mathematical formula:

Disease Index $=\frac{\sum a \times b}{N \times K} \times 100 \%$.

where $a$ is the number of leaves with the corresponding infection degree, $b$ is the infection degree of leaves (scale differences from $0-5$ ), $N$ is the total number of leaves counted in a plant, and $K$ is the maximal value of lesion intensity (= 5 on the chosen scale) [42]. Data were subjected to one-way analyses of variance (ANOVA) and mean separation was performed using the least significant difference (LSD) test $(\mathrm{a}=0.05)$.

\subsection{Treatment and extraction of leaf material}

Four-leaf pumpkin plants were randomly assigned into four groups. The four treatments studied were plants sprayed with $100 \mu \mathrm{g} \cdot \mathrm{mL}^{-1}$ osthol (referred to as SO), plants sprayed with water (referred to as WO), osthol-pretreated plants inoculated with S. fuliginea (inoculation was carried out on the second day of osthol treatment, referred to as SI) and non-osthol pretreated plants inoculated with $S$. fuliginea (inoculation was carried out on the second day, referred to as WI). When the osthol solution was sprayed on SO and SI plants, the same volume of water was sprayed on WO and WI plants. The top extended leaves were collected at time course of $1,2,3,4,6,8$ and 10 days after the treatment (inoculation was performed immediately after second collection of leaves). Leaf tissues (exactly $0.3 \mathrm{~g}$ ) were ground in liquid nitrogen and homogenized in Tris-HCI (0.05 M, pH 8.0, $3 \mathrm{~mL})$. The homogenates were centrifuged for $20 \mathrm{~min}$ at $3,500 \mathrm{~g}$. The supernatants were used as enzyme sources for the following enzyme assay.

To investigate the expression of chitinase gene in pumpkin response to osthol treatment, inoculated plants was sprayed with $100 \mu \mathrm{g} \cdot \mathrm{mL}^{-1}$ osthol. Four days after treatment, the top extended leaves were sampled for RT-PCR analysis. The non-inoculated plants sprayed with water served as control. RNA extraction was performed using Simply P Total RNA Extraction kit (Bloer Technology CO., Hangzhou, 
P.R. China). The RNA was solubilized in sterilized distilled water and reprecipitated in 0.25 volume 3.0 $\mathrm{M}$ potassium acetate and 2.5 volumes ethanol and stored at $-80{ }^{\circ} \mathrm{C}$ prior to quantification.

\subsection{Enzyme Assays}

\subsubsection{Chitinase activity}

Chitinase activity was assayed by measuring the amount of the reducing end group, GlcNAc (Nacetyl-b-D-glucosamine), produced from colloidal chitin. The assay mixture consisted of enzyme extract $(0.3 \mathrm{~mL})$ and $1.0 \%$ colloidal chitin $(0.2 \mathrm{~mL})$. After incubation at $37^{\circ} \mathrm{C}$ for $1 \mathrm{~h}$, the mixture was inactivated in boiling water for $5 \mathrm{~min}$. After centrifugation at 5,000 rpm for $10 \mathrm{~min}$, supernatant liquid $(0.2 \mathrm{~mL})$ was kept in a boiling water bath for $3 \mathrm{~min}$. After cooling down, potassium borate solution $(0.8 \mathrm{M}, 0.1 \mathrm{~mL})$ and $1 \%$ DMAB $(3 \mathrm{~mL})$ were added in the supernatant. After incubation at $36{ }^{\circ} \mathrm{C}$ for 20 min, the value of absorbency for each treated sample was detected at $544 \mathrm{~nm}$ using a spectrophotometer. The activity was calculated from a standard curve based on known concentrations of $N$-acetyl- $\beta$ - $D$-glucosamine. The chitinase activity was defined as the amount of liberated GlcNAc hour $^{-1}$ gram fresh weight ${ }^{-1}[43]$.

\subsubsection{POD activity}

Peroxidase activity was determined at $30{ }^{\circ} \mathrm{C}$ by a modified spectrophotometric method [44]. The reaction mixture consisted of plant extract $(0.1 \mathrm{~mL}), 0.05 \mathrm{M}$ guaiacol $(1 \mathrm{~mL}), 50 \mathrm{mM}$ sodium phosphate buffer $(\mathrm{pH} 6.0,2.9 \mathrm{~mL})$. The reaction was started by addition of $2 \% \mathrm{H}_{2} \mathrm{O}_{2}(1 \mathrm{~mL})$. The reaction was incubated in a water bath and absorbance at $470 \mathrm{~nm}$ was recorded every $15 \mathrm{~s}$ for one minute. Peroxidase activity was expressed as $\Delta$ absorbance $470 \min ^{-1}$ gram fresh weight ${ }^{-1}$.

\subsubsection{PAL activity}

Phenylalanine amonia-lyase activity was determined by the modified method of [45]. The reaction mixture contained leaf extract $(0.3 \mathrm{~mL}), 0.2 \mathrm{M}$ phenylalanine solution $(1 \mathrm{~mL})$ and $0.05 \mathrm{M}$ borate buffer $(\mathrm{pH} 8.8,2.7 \mathrm{~mL})$. The reaction was quenched with $6 \mathrm{~N} \mathrm{HCl}(0.1 \mathrm{~mL})$. The production of cinnanate during $1 \mathrm{~h}$ at $30^{\circ} \mathrm{C}$ was measured by the absorbance change at $290 \mathrm{~nm}$. PAL activities were expressed as $\Delta$ absorbance $(290 \mathrm{~nm}) \mathrm{min}^{-1}$ gram fresh weight ${ }^{-1}$. In case of every enzyme under investigation of these trials, each treatment consisted of three replicates and three spectrophotometric readings were taken per replicate. The Tukey test was used for comparing means.

\section{$3.5 R T-P C R$}

In preparation for RT-PCR, RNA samples from the pumpkin were transcribed into DNA using First Strand cDNA Synthesis Kit (Toyobo Co., Japan). The resulting fist strand cDNA was used for PCR. PCR for chitinase gene (Chitin) was performed with the forward primer 5'ACTGCCGCTCAATCCTTC-3' and the reverse primer 5'-ATGGCTTGTTTCCTTGTGGT-3' (primer designed according to online sequence, E13289). The primers were synthesized by Nanjing Sunshine Biotechnology Co., Ltd. (P.R. China). Actin, constitutively expressed in the plant, was assayed as 
internal control. The primer pairs: 5'-ATGCTGCTACTCGTAAACG-3' (Forward), 5CAAATGGCTGTCTTGAATGC-3' (Reverse) were used to detect actin transcript. Reaction mixture $(50 \mu \mathrm{L})$ consisted of PCR Buffer $(10 \mathrm{x}, 5 \mu \mathrm{L})$, dNTP mixture (10 mM, 1 $\mu \mathrm{L}), \mathrm{MgCl}_{2}(25 \mathrm{mM}, 3 \mu \mathrm{L})$, Primer mix (10 $\mu \mathrm{M}$ each, $2.5 \mu \mathrm{L})$, template DNA (cDNA, $1 \mu \mathrm{L})$, Taq DNA Polymerase $(0.5 \mu \mathrm{L})$ and autoclaved, distilled water. The following program was performed: $94{ }^{\circ} \mathrm{C}$ for 3 minutes then followed by 27 cycles of $94{ }^{\circ} \mathrm{C}$ for $1 \mathrm{~min}, 52^{\circ} \mathrm{C}$ for 40 seconds, and $72{ }^{\circ} \mathrm{C}$ for 1 minute. The products are finally extended at $72^{\circ} \mathrm{C}$ for $5 \mathrm{~min}$. PCR efficiency was tested by agarose gel electrophoresis.

\section{Acknowledgements}

This research was supported by the National Natural Science Foundation of China (30471125).

\section{References}

1. Rémus-Borel, W.; Menzies, J.G.; Bélanger, R.R. Silicon induces antifungal compounds in powdery mildew-infected wheat. Physiol. Mol. Plant Pathol. 2005, 66, 108-115.

2. Fofana, B.; Mcnally, D.J.; Labbé, C.; Boulaner, R.; Benhamou, N.; Séguin, A.; Bélanger, R.R. Milsana-induced resistance in powdery mildew-infected cucumber plant correlates with the induction of chalcone synthase and chalcone isomerase. Physiol. Mol. Plant Pathol. 2002, 61,121132

3. Tuzun, S.; Rao, M.N.; Vogeli, U.; Schardi, C.L.; Kuc, J. Induced systemic resistance to blue mold: early induction and accumulation of $\beta$-1,3-glucanases, chitinases, and other pathogenesis-related proteins (b-proteins) in immunized tobacco. Phytopathology 1989, 79, 979-983.

4. Bartnicki-Garcia, S. Cell wall chemistry, morphogeneseis, and taxonomy of fungi. Ann. Rev. Microbiol. 1968, 22, 87-108.

5. Broekaert, W.F.; Van Parijs, J.; Allen, A.K.; Peumans, W.J. Comparison of some molecular, enzymatic and antifungal properties of chitinases from thorn-apple, tobacco and wheat. Physiol. Mol. Plant Pathol. 1988, 33, 319-331.

6. Schlumbaum, A.; Mauch, F.; Vogeli, U.; Boller, T. Plant chitinases are potent inhibitors of fungal growth. Nature 1986, 324, 365-367.

7. Shinshi, H.; Mohnen, D.; Meins, F. Regulation of a plant pathogenesis-related enzyme: inhibition of chitinase and chitinase mRNA accumulation in cultured tobacco tissues by auxin and cytokinin. Proc. Nat. Acad. Sci. U.S.A. 1987, 84, 89-93.

8. Vogeli-Lange, R.; Hansen-Gehri, A.; Boller, T.; Meins, F. Induction of the defense-related glucanohydrolase, $\beta$-1, 3-glucanase and chitinase, by tobacco mosaic virus infection of tobacco leaves. Plant Sci. 1988, 54, 171-176.

9. Roby, D.; Broglie, K.; Cressman, R.; Biddle, P.; Chet, I.; Broglie, R. Activation of a bean chitinase promoter in transgenic tobacco plants by phytopathogenic fungi. Plant Cell 1990, 2, 999-1007.

10. Conrads-Strauch, J.; Dow, J.M.; Milligan, D.E.; Parra, R.; Daniels, M.J. Induction of hydrolytic enzymes in Brassica campestris in response to pathovars of Xanthomonas campestris. Plant Physiol. 1990, 93, 238-243.

11. Pharmacopoeia of the People's Republic of China (English Edition, 1997); Chemical Industry Press: Beijing, People's Republic of China, 1997; 1, 62-63. 
12. Ou, M. Chinese-English manual of commonly used traditional Chinese medicine; Joint Publishing Co., Ltd.: Hong Kong, 1989; p. 522.

13. Matsuda, H.; Tomohiro, N.; Ido, Y.; Kubo, M. Anti-allergic effects of Cnidii Monnieri fructus (dried fruits of Cnidium monnierz) and its major component, osthol. Biol. Pharm. Bull. 2002, 25, 809-812.

14. Liao, J.M.; Zhu, Q.A.; Lu, H.J.; Li, Q.N.; Wu, T.; Huang, L.F. Effects of total coumarins of Cnidium monnieri on bone density and biomechanics of glucocorticoids induced osteoporosis in rats. Acta Pharmacol. Sin. 1997, 18, 519-521.

15. Ojala, T. Biological screening of plant coumarins. Academic Dissertation; University of Helsinki: Helsinki, Finland, 2001; pp. 42-45.

16. Shukla, Y.N.; Srivatava, A. Phytotoxic and antimicrobial constiuents of Argyreia speciosa and Oenothera biennes. Ethnopharmacology 1986, 67, 241-245.

17. Shi, Z.Q.; Shen, S.G.; Xu, L.L.; Fan, Y.J. Inhibition Mechanism of Osthol to Plant Fungus Pathogens. Chin. J. Pest. Sci. 2004, 6, 28-32.

18. Abenavoli, M.R.; Sorgona, A.; Muscolo, A. Morphological changes in tissue culture of Petunia hybrida in response to coumarin allelochemical. Allelopat. J. 2001, 8, 171-177.

19. Abenavoli, M.R.; Sorgona, A.; Albano, S.; Cacco, G. Coumarin Differentially Affects the Morphology of Different Root Types of Maize Seedlings. J. Chem. Ecol. 2004, 30, 1871-1883.

20. Métraux, J.P.; Burkhart, W.; Moyer, M.; Dincher, S.; Middlesteadt, W.; Williams, S.; Payne, G.; Carnes, M.; Ryals, J. Isolation of a complementary DNA encoding a chitinase with structural homology to a bifunctional lysosyme / chitinase. Proc. Nat. Acad. Sci. U.S.A. 1989, 86, 896-900.

21. Gozzo, F. Systemic acquired resistance in crop protection: from nature to a chemical approach. $J$. Agric. Food Chem. 2003, 51, 4487-4503.

22. Soylu, S.; Baysal, Ö.; Soylu, E.M.. Induction of disease resistance by the plant activator, acibenzolar-Smethyl (ASM), against bacterial canker (Clavibacter michiganensis subsp. michiganensis) in tomato seedlings. Plant Sci. 2003, 165, 1069-1075.

23. Zimmerli, L.; Jakab, G.; Me'traux, J.P.; Mauch-Mani, B. Potentiation of pathogen-specific defense mechanisms in Arabidopsis by $\beta$-aminobutyric acid. Proc. Nat. Acad. Sci. U.S.A. 2000, 97, 1292012925.

24. Boller, T.; Gehri, A.; Mauch, F.; Vogeli, U. Chitinase in bean leaves: induction by ethylene, purification, properties, and possible function. Planta 1983, 157, 22-31.

25. Nasser, W.M.; de Tapia, M.; Kauffmann, S.; Montasser-Kouhsari, S.; Burkard, G. Identification and characterization of maize pathogenesis-related proteins. Four maize PR proteins are chitinases. Plant Mol. Biol. 1988, 11, 529-538.

26. Hammerschmidt, R.; Nuckles, E.; Kuc, J. Association of enhanced peroxidase activity with induced systemic resistance of cucumber to Colletotrichum lagenarium. Phys. Plant Physiol. 1982, 20, 73-80.

27. Benhamou, N. Elicitor-induced plant defense pathways. Trends Plant Sci. 1996, 1, 233-240.

28. Hahlbrock, K.; Scheel, D. Physiology and molecular biology of phenylpropanoid metabolism. Ann. Rev. Plant Physiol. Plant Mol. Biol. 1989, 40, 347-369. 
29. Zhang, C.H.; Fevereiro, P.S.; He, G.Y.; Chen, Z.J. Enhanced paclitaxel productivity and release capacity of Taxus chinensis cell suspension cultures adapted to chitosan. Plant Sci. 2007, 172, 158-163.

30. Hammerschmidt, R. Phenols and plant-pathogen interactions: The saga continues. Physiol. Mol. Plant Pathol. 2005, 66, 77-78.

31. Terry, L.A.; Joyce, D.C. Elicitors of induced disease resistance in postharvest horticultural crops: a brief review. Postharv. Biol. Tech. 2004, 32, 1-14.

32. Kunz, W.; Schurter, R.; Maetzke, T. The chemistry of benzothiadiazole plant activators. Pest. Sci. 1997, 50, 275-282.

33. Oostendorp, M.; Kunz, W.; Dietrich, B.; Staub, T. Induced disease resistance in plants by chemicals. Eur. J. Plant Pathol. 2001, 107, 19-28.

34. Mucharromah, E.; Ku'c, J. Oxalate and phosphates induce systemic resistance against diseases caused by fungi, bacteria and viruses in cucumber. Crop Prot. 1991, 10, 265-270.

35. Sticher, L.; Mauch-Mani, B.; Metraux, J.P. Systemic acquired resistance. Ann. Rev. Plant Pathol. 1997, 35, 235-270.

36. Watanabe, T. Effects of probenazole (Oryzemater) on each stage of rice blast fungus (Pyricularia oryzae Cavara) in its life cycle. J. Pest. Sci. 1977, 2, 395-404.

37. Cohen, Y. Induced resistance against fungal diseases by aminobutyric acids. In Modern Fungicides and Antifungal Compounds; Lyr, H.; Russell, P.E.; Sisler, H.D., (eds.); Intercept: Andover, UK, 1995; pp. 461-466.

38. Tosi, L.; Luigetti, R.; Zazzerini, A. Induced resistance against Plasmopara helianthi in sunflower plants by DL-betaamino-n-butyric acid. J. Phytopathol. 1998, 146, 295-299

39. Langcake, P.; Cartwright DWand Ride, J.P. The dichlorocyclopropanes and other fungicides with indirect mode of action. In Systemische Verbindungen und antifungale Verbindungen; Lyr, H.; Polter, C. (eds.); Akademie-Verlag: Berlin. 1983; pp. 199-210.

40. Mauch-Mani, B. Arabidopsis-pathogen interaction: a model system for the analysis of acquired resistance. Proceedings 14th Int. Plant Protect. Cong. Jerusalem, 1999; p. 131

41. Siegrist, J.; Orober, M.; Buchenauer, H. $\beta$-Aminobutyric acid-mediated enhancement of resistance in tobacco to tobacco mosaic virus depends on the accumulation of salicylic acid. Physiol. Mol. Plant Pathol. 2000, 56, 95-106

42. Shternshis, M.V.; Beljaev, A.A.; Shpatova, T.V.; Bokova, J.V.; Duzhak, A.B. Field testing of bacticide, phytoverm and chitinase for control of the raspberry midge blight in Siberia. BioControl 2002, 47, 697-706.

43. Boller, T.; Metraux, J. P. Colorimentric assay for chitinase. Meth. Enzymol. 1988, 161, 430-435.

44. Chance, B.; Maehly, A.C. Assay of catalases and peroxidases. Meth. Enzymol. 1955, 2, 764-775.

45. Cheng, G.W.; Breen, P.J. Activity of phenylanaline ammonialyase (PAL) concentrations of anthocyanins and phenolics in developing strawberry fruit. J. Am. Soc. Hort. Sci. 1991, 116, 865869.

(C) 2007 by MDPI (http://www.mdpi.org). Reproduction is permitted for noncommercial purposes. 